\title{
CÓDIGO DO DIREITO PRIVADO: APENAS TRÊS ARGUMENTOS
}

\author{
Antonio Sérgio Altieri de Moraes Pitombo \\ Aluno de Graduação da Faculdade de Direito da Universidade de São Paulo.
}

Resumo: O trabalho visa mostrar três diferenças entre o Direito Civil e o Direito Comercial. É discutida a idéia de código, o caráter cosmopolita do Direito Comercial e, ainda, a Teoria das Fontes, sob o prisma de princípios de fisica.

\begin{abstract}
This paper tried to show three differences between Civil and Commercial Law. First of all, the idea of code is discussed. Secondlly, under historical points, the cosmopolitan aspect of commercial law is analysed. Finally, ideas of physics and law are mixed.

Unitermos: O Papel dos Códigos; Caráter Cosmopolita; Distinções dos dois ramos; Adição de Princípios de Física; Teoria das Fontes.
\end{abstract}

"na atual crise de valores, o mundo pede aos juristas idéias novas, mais que sutis interpretações" (Tullio Ascarelli)

\section{Introdução}

Não deve se espantar quem com tal estudo se depara, quando vê tão extenso tema reduzido a três argumentos sucintos.

A justificativa, poder-se-ia encontrá-la na tentativa de restringir a análise, buscando em pontos específicos, trabalhar as idéias predominantes na cultura jurídica contemporânea, dentro de novos caminhos.

A ambição, tem de se concordar, não se desenha tão pequena.

O primeiro raciocínio se limita a examinar o papel dos códigos. $O$ segundo, sob prisma histórico, investiga o caráter cosmopolita do direito comercial. Finalmente, o ultimo e mais difícil, se degladia para marcar as distinções dos dois ramos do Direito: Civil e Comercial, a partir da adição de princípios de física à teoria das fontes.

O resultado, só os mais doutos estão aptos a dizer se positivo. Trazê-lo ao prelo emerge, somente, meio de me livrar do dilema de Borges: publicar ou dispender a vida em aprimoramentos. Há, afinal, sempre algo a corrigir. 


\section{Parte 1 - Código: nova função}

Em 1825, Pereira e Souza ${ }^{(01)}$ definiria o vocábulo código:

"Esta palavra vem da Latina Codex, que em geral quer dizer Colleção, mas em sentido de jurisprudência he a Colleçāo de Direito, ou de lei, ou composta por authoridade do Soberano, ou pelo zelo de alguns jurisconsultos particulares".

Ainda, que incompleto, o conceito nos fornece perfil do que se pensara, no início do século XIX, sobre o assunto.

Observe-se que a codificação, no primeiro instante, se apresenta simples conjunto ou reunião, privada ou oficial, de leis da mesma natureza ou que têm qualquer relação entre si.

Poder-se-ía crer que tal concepção provém do citado termo romano Codex, o qual designou as coletâneas de fontes jurídicas (Codex Gregorianus, Codex Hermogenianus, Codex Theodosianus, Codex Justianus e outros).

Mais adiante, o próprio Pereira e Souza, de modo curioso, escreveria:

"Ultimamente se publicou em 1804 o Codigo Civil dos franceses concebido em ordem systematica. He tambem systematico o Codigo Frederico..."

Aqui, numa acepção mais específica, adequada às idéias do séc. XVIII e princípios do séc. XIX, o autor percebe que, de mera compilação, os diplomas legislativos passam a ser elaborados segundo critérios sistemáticos e científicos, os quais respeitam a todo um importante setor, ou ramo, do direito e se destinam a regulá-lo duradouramente a partir de certo momento. Conforme ensina Mário Bigotte Chorão ${ }^{(02)}$, eram: "Conjunto de elementos postos em conjugação funcional."

As codificações, como sistema, inserem-se numa nova forma de conceber o Estado. Correspondem, pois, às exigências políticas de seu tempo.

Variadas ideologias, conseqüentemente, surgem no movimento codificador. Para Pufendorf, o direito consiste em mandatos emanados de uma autoridade. Para Leibniz, de índole racionalista, o direito é um sistema de proposições fundadas na natureza das coisas e nos ditames da reta razão.

Os códigos emergem como a identificação do direito com o sistema normativo, garantido pelo poder coativo estatal. Os códigos são, portanto, expressão máxima do positivismo jurídico.

As codificaçōes tentaram racionalizar a multiplicidade, muitas vezes, confusa e dispersiva, das fontes do direito. Buscou-se unidade, bem como, clareza, como expressa Tércio Sampaio Ferraz Jr.:

"Os códigos, não obstante, representam uim esforço técnico de domínio prático de um material, conforme as exigências de decidibilidade de conflitos em uma sociedade complexa, submetida à celeridade das transformaçōes" ${ }^{(03)}$.

Seriam o instrumento, o qual tornava mais fácil o conhecimento e a aplicação do sistema normativo.

Parece, no entanto, que o aspecto a ser hipervalorizado surge a segurança jurídica, pois as codificações transmitem cognoscibilidade, estabilidade e previsibilidade do direito, de modo a poder cada um saber aquilo a que se ater na ordem jurídica ${ }^{(04)}$.

Além disso, limitariam o poder estatal, preocupação esta originada, provavelmente, nas obras dos autores do oitocentos. 
A construção da crítica ao movimento codificador, em contrapartida, poderia ser elaborada no tocante ao imobilismo legislativo, ao conservadorismo doutrinal e à idolatria legalista. A última tão ao gosto dos lusos-brasileiros, por força das quatro Ordenaçōes: Afonsinas, Manuelinas, Sebastiânicas e Filipinas.

Tércio Sampaio Ferraz Jr. escreveu: "Os códigos que conhecemos hoje são marcados por um espirito de rigidez e conservadorismo que contrasta, mas fornece uma impressäo de segurança e certeza, com a mutabilidade multefaria da civilizaçāo industrial nos quadros do predomínio do Estado-gestor e das exigências da unidade política" $^{(05)}$.

Aqui, o ponto-fundamento, o qual não pode ser esquecido: o código único, como sistema que se propõe a englobar parte geral e parte especial, foge à dinâmica das necessidades da sociedade (capitalista, em principal) contemporânea.

O Estado, hoje, tem que, por meio de leis, dar respostas eficientes às questões, nascidas nas relações econômicas, por exemplo. E, conjuntamente, tem dever de proteger as camadas prejudicadas da população, numa determinada circunstância histórica.

Neste sentido, Fábio Konder Comparato: ${ }^{(06)}$

"O Estado Social não se legitima simplesmente pela produçäo de direito, mas antes de tudo pela realizaçāo de políticas (policies), isto é, programas de açāo".

$\mathrm{O}$ Estado não só intervém na ordem social como produtor de direito e realizador de segurança, mas passa a desenvolver novas formas de atuação, para o que faz uso do direito positivo, como meio de implementação de políticas públicas ${ }^{(07)}$.

O Código, como predefinimos, contém matérias afins, organizadas por critério sistemático. Daí, a idéia de conjunto funcional ou operacional, antes mencionada. Quando em medida provisória ou lei complementar, consideradas como instrumento jurídico de política pública, há diversa regulamentação sobre a matéria pertinente à código específico, temos ou não, quebra do sistema?

A resposta parece positiva, afinal os elementos, constitutivos do todo, deixam de ser coordenados entre si, passando a existir fragmentação necessária do conjunto, graças aos anseios da sociedade por respostas mais eficazes.

Ao pensarmos, concluindo, na unificação do direito privado, em Código uno, estamos cometendo engano.

Poderia-se, preliminarmente, criticar o mito que envolve as codificações, o qual ilude o jurista ligado à dogmática, como ciência dos dogmas jurídicos, expressos em lei. Note-se que tal mito obriga o "legislador a se esmerar num casuísmo exaustivo" ${ }^{(08)}$, visando à satisfação das questões trazidas pelo cotidiano.

Momento, talvez, fosse de se reavaliar a idéia de código e a sua respectiva função. Fábio Konder Comparato, sugere, na trilha do ensinamento de Ascarelli:

"... a funçāo precípua de um código é exprimir um conjunto de regras jurídicas gerais, constituintes de um novo jus commune, que enforma e ilumina a interpretação desse mare magnum da legislação extravagante" ${ }^{\prime 09)}$.

Conseqüentemente, a unificação do direito privado em si se mostra censurável, quando analisamos as origens, os princípios e a aplicação dos dois ramos do direito. Se o código deve conter princípios gerais, não se podem combinar 
Direito Civil e Comercial. A unificação traria dificuldade imensa, por exemplo, para se disciplinarem, coerentemente ao sistema, os títulos de crédito.

Enfim, descuido há ao se ignorar a face fragmentária do direito. Hoje, é notável que partes do Direito Comercial se vão destacando aos poucos: direito bancário, marítimo, cooperativo, de seguro e da propriedade industrial. Tratam-se das partes especiais, as quais, à medida das necessidades da realidade, podem ser modificadas.

\section{Parte 2 - O Caráter Cosmopolita do Direito Comercial: Aspectos Histórico- Jurídicos}

O jurista se torna desnecessário, quando encherga o direito como algo distante da realidade concreta, presente ou passada.

Repensar os institutos, sob prisma histórico, emerge obrigação suprema daquele que pretende compreender o fenômeno jurídico, para além da ética da conveniência. Observe-se, contudo, que a conceituação de história muito se tem alterado neste século. Hoje, refutam-se: "uma história idealista, onde as idéias se geram por uma espécie de partogênese, ... uma história guiada pela concepção de um progresso linear, ... uma história que interpreta o passado com os valores do presente. Pelo contrário, François Jacob propöe a história numa ciência que da conta das condições (materiais, sociais, mentais) da sua produção e que individualiza, em toda a sua complexidade, as etapas do saber" (Jacques Le Goff). (10)

Régine Pernoud é uma das historiadoras que muito contribuiu para a compreensão da Idade Média, dentro dos novos conceitos e métodos de investigação. Em seu livro, As origens da Burguesia ${ }^{(11)}$, aponta bem que o comércio medieval; a partir do século $\mathrm{X}$, passou a ser uma ampla corrente de trocas, que conduz aos mercados europeus produtos da Ásia Menor, transportados pelas caravanas, até os postos ou às cidades comerciais da Síria, do Egito e da África do Norte. Complementa, então:

"Deste movimento surgiu e multiplicou-se uma populaçāo cuja densidade, no quadro da sociedade feudal do século $X$, era imposstvel prever. A burguesia nascera, $\dot{e}$ como representava uma força inteiramente nova, teve que criar o seu lugar nesse mundo. Cada qual, na sociedade medieval, desfrutara os privilégios inerentes ao seu estado: o burguês tinha necessidade de certos privilégios. Em primeiro lugar, tinha necessidade de liberdade de circulação".

Tal liberdade de circulação terminou por criar necessidade de um direito de caráter internacional, ou transnacional, que bem se distinguisse do Direito Romano.

Note-se, portanto, que "um novo espírito empreendedor do burguês .e uma nova organização dos negócios", nas palavras de Tullio Ascarelli ${ }^{(12)}$, acabaram dando à luz a práticas, as quais se podem considerar verdadeiros embriōes do Direito Comercial.

Assim, apesar dos avanços no estudo do Direito Romano durante o século XII, na Itália, e século XIII em outros locais da Europa, o mesmo não satisfazia, por exemplo, às necessidades da atividade mercantil. Havia ruptura entre o direito romano-canônico comum e as práticas econômicas, postas em emergência nova. 
Tullio Ascarelli (13), citando Benvenuto Stracca, autor do século XVIII, aproxima o direito comercial ao jus gentium. Contudo, a idéia de jus gentium, da qual se utiliza, não é a romana: "direito dos estrangeiros dentro do território". Mas, sim, a de Jeremias Bentham, que ampliou o conceito: "direito comum a todos os povos", ou International Law ${ }^{(14)}$.

Observe-se que o caráter universal do Direito Romano desapareceu com o fortalecimento dos Estados Nacionais.

Veja-se, ainda, que o Direito Romano, apesar de perder sua universalidade, continuou vivo. Os Estados Nacionais justificaram a criação de um direito próprio mirando-se no exemplo do Direito Romano (direito oriundo de estado centralizado). Além disso, boa parte dos seus institutos seria transferida às novas ordenações jurídicas ${ }^{(15)}$.

Ascarelli apontou:

"De um lado, a lo largo del siglo XVII, se fueron fortalecoendo los Estados Monarquicos centralizados que luego reivindicaron para si el monópolio de la funcion legislativa. El derecho comercial pasa entonces a formar parte del derecho estatal... a diferencia de lo que acontecio con los demás derechos autonomos de determinadas clases sociales... no es absorvido por el derecho comum; por el contrário... no solo conserva su autonomia... sino que influencia el propio derecho comum..." ${ }^{(16)}$.

O Direito Comercial nasceu, quando da fragmentação do antigo direito entre as nações, que se moldavam. $O$ comércio continúava sendo o modo pelo qual os Estados se aproximavam.

Muito bem comprovam, a relação dos povos por meio do comércio, as leis do século XIV, chamadas Las Siete Partidas, na Quinta Partida, título VII, Lei III:

"Onde mandamos, q todos los que viniere a las ferias de nuestros reynos, tan bié cristianos, como judios, e moros: e otrosi los que viniere en otra sazon, qualquier, a nuestro senorio: maguer non venga a ferias, que sean salvos, e seguros, sus cuerpos, $e$ sus mercadurias, e todas sus cosas, tambien en mar, como en tierra, en viniendo a nuestro senorio, e estando y, en yendose de nuestra tierra" (17).

O caráter supranacional do Direito Comercial, pode ser constatado na Lei da Boa Razão de 1769:

"Ou aquela boa razão que se estabelece nas Leis Políticas, Econômicas, Mercantis e Marítimas, que as mesmas nações cristãs têm promulgado... em casos de necessidade ao subsídio" (18).

Fundamental, também, a obra de José, da Silva Lisboa, Visconde de Cayru, que cuidadosamente trata da matéria ${ }^{(19)}$.

Muitos autores se apóiam neste argumento, na defesa da separação, como Cesare Vivante que, no $\$ 3$ do seu Tratado de Direito Comercial, se dedica à Indole Cosmopolita do Comércio e do Direito Comercial que o governa ${ }^{(20)}$.

$\mathrm{O}$ aspecto cosmopolita pode ser confirmado, sem empirismo algum, quando se percebe, por exemplo, que o Direito Comercial herdou: o endosso, que revolucionou a letra de câmbio dos franceses; os negócios em bolsa, dos primeiros praticados em Flandres $\mathrm{e}$ as patentes de invenção dos estatutos ingleses dos monopólios, que tinha precedente em Veneza dos séculos XV e XVI (conforme Ascarelli). ${ }^{(21)}$ 
A condensação dos institutos observados na prática de diversos países, caminhando do sistema subjetivo a um sistema objetivo, teve triunfo no Código Napoleônico.

Interessante, porém, se faz notar que o sistema objetivista, forma de expressão do poder do Estado, significa segurança jurídica. Era o comerciante em busca de garantias.

\section{Parte 3 - A Dinâmica no Direito Comercial}

Galileu demonstrou que a tradição aristotélica estava enganada, quanto a dois aspectos: Primeiro, quando acreditava que era possivel formular todas as leis, que governam o universo, unicamente, pọ meio do pensamento, sem a necessária comprovação objetiva; Segundo, ao afirmar ser a inércia o estado natural dos corpos. ${ }^{(22)}$

As suas idéias surgem, pois, como efeito de processo construído, com a combinação de elementos ou dados.

Galileu deve, provavelmente, ter ordenado, pela compreensão, ou repulsa, os pensamentos, inclusive os oriundos do passado, adicionando-lhes a observação da realidade, para chegar à devida conclusão (método científico).

Toda esta seqüência, (construção) se tornaria, posteriormente, um dado na elaboração de novos princípios de física (dinâmica do sistema).

O direito, como sistema, "não é essencialmente um dado, mas uma construção elaborada no interior da cultura humana" (Teoria das Fontes) ${ }^{(23)}$.

Quando se medita sobre a distinção entre o Direito Civil e o Comercial, fazem-se essenciais o conhecimento da teoria das fontes e as suas classificações:

"De um lado temos, assim, as fontes substanciais, que são dados, como é o caso dos elementos materiais (biológicos, psicológicos, fisiológicos) que não sāo prescriçōes, mas que contribuem para a formação do direito, dos elementos históricos (representados pela conduta humana no tempo, ao produzir certas habitualidades que $v \bar{a} 0$, aos poucos, sedimentando-se), ou dos elementos racionais (representados pela elaboraçäo da razäo humana sobre a própria experiência da vida, formulando princípios universais para a melhor correlaçäo entre meios $e$ fins) $e$ dos elementos ideais (representados pelas diferentes aspiraçöes do ser humano, formuláveis em postulados valorativos dos seus interesses)" (24).

Para comprovar a diferenciação do civil/comercial, cumpre observar que seus dados se apresentam, manifestamente, distintos, quando observados.

O elemento material, sob o aspecto psicológico, no Direito Comercial, se configura na intenção do homem, participante da atividade mercantil, de sobreviver em sociedade, graças ao lucro de seus empreendimentos ${ }^{(25)}$.

No Direito Civil, as relações de patrimonialidade se apresentam genéricas, podendo ser esparsas no tempo, e não se caracterizam pela vontade do sujeito de subsistir por meio de bem-sucedidas e constantes transaçōes.

O elemento histórico parece, claramente, distinto nos dois. No Direito Comercial, aliás, as suas origens próximas, citadinas na Idade Média, foram a conseqüência da inoperalidade ou ineficiência do direito romano-canônico, frente às necessidades da burguesia. Impossível seria compreendê-lo em determinadas 
normas e cláusulas contratuais sem o estudo histórico, como ensina Tullio Ascarelli (26)

O elemento racional diverge quando, no Direito Comercial, o jurista fica obrigado a sistematizar o novo material, que a prática mercantil cria, com excessiva rapidez.

O elemento ideal, no Direito Civil, se desenha no bem resolver os conflitos de ordem privada. Já o Código Comercial vem regular, especificamente, a atuação humana no campo dos negócios. Não há, pois, diversidade, mas sim, especialidade da norma de Direito Comercial, voltada às idéias de empresa e empresário.

Retornando-se às teorias das fontes:

"De outro lado, fala ele (François Geny) em fontes formais, correspondendo ao construido, significando a elaboração técnica do material (fontes substanciais) por meio de fórmas solenes que se expressam em leis, normas consuetudinárias, decretos reguladores, etc..." $(27)$.

A distinção, aqui, pode ser expressada pela afirmação do hipervalor do costume dentro do Direito Mercantil (ver arts. 130 e 131, n. 4 do Cód. Comercial), o que não ocorre com o Direito Civil, o qual foi racionalizado pelos legisladores temerosos ao Ancien Regime.

Tal aspecto vem, seguidamente, abordado por John Gilissen:

"O costume, pelo menos na aparência, deixou de desempenhar qualquer papel como fonte de direito desde a época da Revoluçāo Francesa.. foi varrido pela legislaçāo revolucionária e pelos códigos napoleônicos.

Certos domínios escaparam, no entanto, à atividade legislativa... Evitou-se, entretanto, empregar o termo costume, que cheirava muito a Antigo Regime, fala-se antes de usos: usos bancórios, usos comerciais, usos profissionais" (grifo meu, 28).

"O Código Civil francês (do século $X I X$ ) nāo contém qualquer texto relativo ao costume como fonte do direito.

Em Direito Civil e em Direito Penal o papel do costume é relativamente limitado.

Em contrapartida, o costume continua a desempenhar um grande papel nos domínios onde há pouca legislaçāo. Antes demais, ,..., nomeadamente no dos grupos sociais profissionalizantes, como os comerciantes" (29)'

Mesmo hoje, o costume ${ }^{(30)}$ tem sua autoridade repousada na força conferida ao tempo e ao uso contínuo ${ }^{(31)}$. Sem esquecer o pouco formalismo.

Poder-se-ia dizer que o tempo seja, também, fator que contribui para a ratificação da norma costumeira, pela ordenação jurídica.

Aqui, mais uma diferença, pois o Direito Comercial é mais veloz que o Civil nesta passagem.

Adicionando-se, numa extrapolação de raciocínio, tal concep̧̧ão ao início do capítulo e às idéias de Galileu, se chega à conclusão de que o costume, como ato reiterado e observado na realidade, sai de seu movimento inercial, tornando-se acelerado e passa a ser norma jurídica em tempo mais curto, dentro da dinâmica do direito comercial. 
Notas

01 - PEREIRA e SOUZA, Joaquim José Caetano, Esboço de Hum Diccionário Juridico, Theorético e Pratico, remissivo às Leis compiladas $e$ extravagantes, Lisboa, Typografia Rollandiana, 1825, T.I, verbete "Código". Deve-se, de plano, observar que o campo de estudo explorado nesta parte 1 foge da análise do direito romano clássico e da commom law. Ascarelli (Tullio), brilhantemente, as fez in Problemas das Sociedades Anônimas e Direito Comparado, São Paulo, Saraiva, 1945, p. 53-98.

02 - CHORÃO, Mário Bigotte, verbete Código, in Polis Enciclopédia Verbo da Sociedade e do Estado, Lisboa-São Paulo, Edit. Verbo, 1983, p. 920-924.

03 - FERRAZ JR., Tércio Sampaio. Introduçäo ao Estudo do Direito, São Paulo, Editora Atlas, 1988, p. 214-5.

04 - Opus cit, Chorão... p. 920; Ascarelli... p.63.

05 - Opus cit, Ferraz Jr. p. 215.

06 - COMPARATO, Fábio Konder. Um Quadro Institucional para o desenvolvimento democrático in Brasil, Sociedade democrática, Hélio Jaguaribe et alii, pp. 407-408 (Conf. Grau, Eros Roberto).

07 - GRAU, Eros Roberto. Contribuição para a interpretação e a crítica da ordem econômica na Constituiçāo de 1988. São Paulo, ed. particular para concurso de professor titular, 1990, p. 19.

08 COMPARATO, Fábio Konder. Projeto de Código Civil in Ensaios e Pareceres de Direito Empresarial, Rio de Janeiro, Edit. Forense, 1978, p. 19.

09 - Opus cit, Comparato, Projeto... p. 545; Ascarelli... p. 70.

10 LE GOFF, Jacques, verbete "História" in Enciclopédia Einaudi, Lisboa, Imprensa nacional - Casa da Moeda, 1968, v.1, p.238.

11 - PERNOUD, Regine. Origem da Burguesia. Póvoa de Varzim, Tipografia Camões, 1973, p.21.

12 - ASCARELLI, Tullio. Corso di Diretto Comerciale - Introduzione e Teoria dell'Imprensa. $3^{\mathrm{g}}$ ed. Milano, A. Giufre, 1962, p. 4.

13 - ASCARELLI, Tullio. Introducion al Derecho Comercial, (trad. Melendo, Santiago Santis). Buenos Aires, Editar SA Editores, 1974, p. 18 e p. 30. 
14 - FRANCO, João Melo e outros. Conceitos e Princípios Jurídicos. Coimbra, Almedina, 1983, p. 496.

15 - Opus cit, Ascarelli... Problemas, p. 55-6.

16 - Opus cit, Ascarelli... Intr... p. 19. Direito Autônomo aqui, entendido como aquele que não se vincula ao direito estatal, fundado no consentimento e nos costumes dos interessados (p.15).

17 - Note-se, aqui, que as leis citadas, tão-somente, servem para mostrar alguns exemplos. Não se tratando, assim, das únicas neste longo período de tempo, o qual implicaria numa pesquisa histórica mais extensa e demorada. Então, como exemplo: Partonaris, Andrea de. Las Siete Partidas. Madrid, Boletim Oficial do Estado, 1974.

18 - Lei da Boa Razão retirada da apostila Evolução do Direito Comercial Luso-Brasileiro, ponto 3 do Curso de Dir. Comercial.(Fdusp, 1990), ministrado pelos profs. Fábio Konder Comparato e Haroldo Malheiros D. Verçosa.

19 SILVA LISBOA, José da. Princípios de Direito Mercantil e Leis da Marinha. Rio de Janeiro, Typografia Acadêmica. 1874.

20 - VIVANTE, Cesare. Tratado de Direito Comercial, *Milão, C. Editrice Francisco Vallardi, 1934 (trad. Verçosa, Haroldo Duclero), apostila do curso de Dir. Comercial (Fdusp, 1990).

21 - Opus cit, Ascarelli... Introd... p. 15.

22. HAWKING, Stephan W. Uma breve História do Tempo, (trad. Torres, Marcia Helena), Rio de Janeiro, Rocco, 1988, p.35.

23 Opus cit, Ferraz Jro, p. 200.

24 - Opus cit, Ferraz Jr., p. 200-1.

25 "A busca de lucratividade não caracteriza nenhum campo de empreendimento como comercial" (Verçosa, Haroldo Malheiros Duclerc, Atividade Mercantil. Ato de Comércio. Mercancia. Matéria de Comércio. Comerciante. in Revista de Direito Mercantil, Industrial, Econômico, Financeiro, $\mathrm{n}^{\mathbf{Q}} 47$, junhosetembro, 1982, p. 30 . Poder-se-ia dizer, contudo, que a habilidade do empresário gera o lucro, o qual permite a feitura de novos negócios, os quais, também, trazem lucro, criando uma cadeia. 


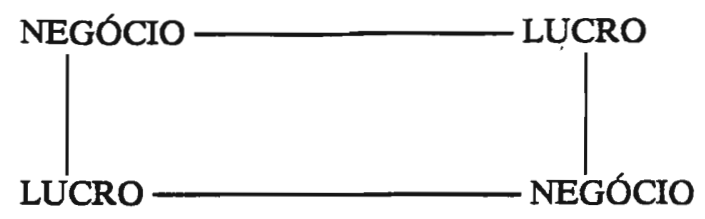

O profissional liberal, o corretor de imóveis e o pequeno agricultor vivem da remuneração recebida pelo seu trabalho na área. Logo, o lucro se faz fundamental para que as suas economias pessoais sobrevivam, mas não é mola-propulsora de sua atividade.

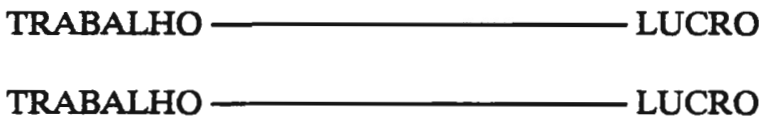

26 - Opus cit, Ascarelli Introducion... p.36.

27 - Opus cit, Ferraz Jr., p.201.

28 - Gilissen, John. Introdução Histórica ao Direito. Lisboa, Fund. Calouste Gulbenkian, 1979, p. 415-6.

29 Opus cit, Gilissen, p. 486. Aqui está a justificativa para o que afirmou Ascarelli: "El derecho comercial se presenta... con un caracter autonomo". Ver: Opus cit, Ascarelli... Introducion... p. 15.

30 - Na discussão sobre a norma consuetudinária jurídica ou não jurídica, adotou-se a solução de Bobbio, Norberto in Teoria do Ordenamento Juridico, São Paulo, Edit. Polis, 1989, p.30.

"Dever-se-à responder, de preferência, que uma norma consuetudinária torna-se jurídica quando vem a fazer parte de um ordenamento jurídico".

31 - Opus cit, Ferraz Jr., p.217.

São Paulo, agosto de 1990. 